\title{
Binge-Watching Behaviour: The Role of Impulsivity and Depressive Symptoms
}

\author{
Sabine Steins-Loeber ${ }^{\mathrm{a}}$ Theresia Reiter $^{\mathrm{a}}$ Heike Averbeck $^{\mathrm{b}}$ Lydia Harbarth $^{\mathrm{b}}$ \\ Matthias Brand ${ }^{\text {b }}$

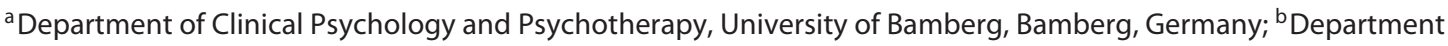 \\ of General Psychology: Cognition, University of Duisburg-Essen, Duisburg, Germany
}

\section{Keywords}

Binge-watching $\cdot$ Impulsivity $\cdot$ Loss of control $\cdot$ Marathon viewing $\cdot$ TV series

\begin{abstract}
Introduction: Following the digital progress and the availability of online streaming services, binge-watching (in the literature often defined as watching $>2$ episodes of a TV series in one sitting) has become a popular viewing pattern. Concerns about possible negative consequences of this behaviour have arisen and its proximity to behavioural addictions is discussed. The aim of the present study was to explore how depressive symptoms, impulsivity and their potential interaction are related to the consequences of binge-watching. In addition, the possible association of the Big 5 personality traits neuroticism, conscientiousness, extraversion, agreeableness, and openness with consequences from binge-watching was assessed. Method: An online survey including the assessment of intensity of and negative consequences from binge-watching (with an adapted version of the Short-Internet-Addiction Test and a newly developed questionnaire) and questionnaires on depressive symptoms (i.e., General Depression Scale), impulsivity (i.e., Barratt Impulsiveness Scale) and personality traits (i.e., short version of the Big 5 Inventory) was completed by 228 participants. Results: Regression analysis indicated that impulsivity was associated with loss of control and neglect of duties,
\end{abstract}

while depressive symptoms led to neglect of duties and social problems. No significant interaction effects were observed. Conscientiousness was the only personality trait that explained a significant proportion of the variance of consequences from binge-watching. Discussion/Conclusion: Our findings suggest that depressive symptoms and impulsivity are 2 independent pathways to negative consequences from binge watching. However, given the rather low proportion of variance proportion explained, future studies are warranted to enhance our understanding of other individual characteristics and to further clarify the proximity to behavioural addictions.

(c) 2020 S. Karger AG, Basel

\section{Introduction}

The last decade has seen an enormous change in the way viewers consume TV. With the development of ondemand viewing and online streaming services, viewers can now decide when and where they want to watch TV, and a wide variety of high-quality TV shows is permanently available at affordable expenses [1]. Especially TV series have become highly sophisticated with complex narrative structures [2] and dramatic techniques that aim at keeping viewers "hooked" [3]. Consequently, the watching of several episodes of one series in a row has become a popular viewing pattern. Although no empiri-

\section{KARGER}

(c) 2020 S. Karger AG, Basel

karger@karger.com

www.karger.com/ear
Prof. Sabine Steins-Loeber

Department of Clinical Psychology and Psychotherapy

Otto-Friedrich-University of Bamberg

Markusplatz 3, DE-96047 Bamberg (Germany)

E-Mail Sabine.Steins-Loeber@uni-bamberg.de 
cally validated definition exists so far, several authors suggested watching $>2$ episodes in one sitting as criterion for binge-watching [4-7].

The excessive involvement with binge-watching has recently become a matter of scientific debate given the loss of control some individual's experience and the possible negative consequences associated with this behaviour [8]. Neglect of important tasks and duties, sleeping problems, fatigue, reduced social contacts and long-term health issues related to inactivity and unhealthy eating are only a few prominent examples $[9,10]$. Some researchers also stress the possibly addictive nature binge-watching might acquire for some individuals and discuss characteristics problematic binge-watching might share with substance-related or behavioural addictions, for example, loss of control over watching, neglect of other activities, and watching to cope with negative emotions [11]. However, it is important to acknowledge also differences to addictive behaviours. These are, for example, social acceptance, transient overinvolvement, context dependen$c y$, and low everyday life impact as outlined by Flayelle et al. [6]. These differences are important to consider in order to prevent the overpathologization [12] of a leisure activity often driven by entertainment motivation [13] and not accompanied by any negative consequences for many individuals.

Given this debate, it is essential to enhance our understanding of the transition from binge-watching as a passion [14] or a positive non-interfering engagement [15] to an excessive and uncontrolled behaviour that is associated with negative consequences, functional impairment in everyday-life and distress. The Interaction of PersonAffect-Cognition-Execution (I-PACE) has been suggested by Brand et al. $[16,17]$ as a theoretical framework for the hypothesized processes, which underlie the development and maintenance of an addictive use of certain Internet applications, such as gaming, pornography use, shopping, and social-networks use. The development of problematic behaviour is considered to develop as a consequence of interactions between neurobiological and psychological predisposing variables (e.g., personality traits, psychopathology like depression) and moderating/ mediating variables such as affective aspects (e.g., craving, motivation to experience pleasure or to reduce negative mood), cognitive aspects (e.g., reward expectancies, coping style, implicit cognitions), executive functions, and decision making. Given the screen-based nature of TV-series watching, the I-PACE-model seems to be a fruitful framework for studying problematic bingewatching. However, at present, research on the role of the different components of this model with regard to bingewatching is very limited.

It can be assumed that a wide variety of individual characteristics might make individuals sensitive to engage in binge-watching (e.g., emotional regulation problems, self-control problems, perceptual and attentional problems). Thus, previous research assessed the role of psychopathology and reported an association between binge-watching and depression $[5,18]$. However, in these studies no clear differentiation was made between the mere time spent binge-watching and binge-watching associated with negative consequences. As these 2 aspects might not be associated, it is important to further enhance our understanding of the role of negative consequences associated with binge-watching and the severity of depressive symptoms.

In this context, it would also be interesting to elucidate further the role of impulsivity as a personality trait, which has been related to several problematic addictive behaviours such as alcohol and drug abuse, gambling disorder [19], and Internet-use disorder [20, 21]. High impulsive individuals tend to have difficulties to focus on tasks, behave on impulse without thinking, and are less likely to think about or plan for the future [22]. Preliminary findings with regard to binge-watching suggest that trait impulsive behaviour (assessed with the Barratt-Impulsiveness Scale [23]) is associated with binge-watching [24]. Similarly, Orosz et al. [25] administered the UPPS Impulsive Behavior Scale [26] and found that higher impulsivity scores were associated with obsessive feelings with regard to binge-watching. However, no studies are available that assessed whether depressive symptoms and impulsivity are 2 independent factors that contribute to the development of negative consequences from binge-watching or whether the interaction of these factors underlies possible problematic binge-watching. Based on the IPACE model $[16,17]$, it can be assumed that impulsivity as a predisposing factor interacts with depressed mood and this interaction aggravates the risk to develop problematic binge-watching behaviours.

Apart from impulsivity, previous research has related further personality traits to binge-watching. For example, Tóth-Király et al. [15] reported that neuroticism, extraversion and agreeableness were positively related to the time spent binge-watching and problematic series watching, while conscientiousness appeared as a protective factor that was negatively correlated to binge-watching. However, the independent contribution of these variables to binge watching when taking into account variables which have been related more closely to problematic be- 
havioural patterns like depressive symptoms and impulsivity $[16,17]$ remains unclear so far.

Against this background, the aim of the present study was to enhance our understanding of psychological processes underlying binge-watching by assessing whether depressive symptoms, impulsivity and their interaction are associated with negative consequences from binge-watching. We hypothesized that strong depressed mood would be associated with the highest levels of binge-watching in individuals reporting high trait impulsivity. In addition, we aimed to assess the unique contribution of other personality traits (i.e., neuroticism, extraversion, agreeableness, openness and conscientiousness) to binge-watching.

\section{Methods}

\section{Participants}

A community sample of 228 participants (148 females, 65\%) with a mean age of 29.79 years (SD 7.03, range 18-58) was recruited via different Facebook groups. No exclusion criteria were defined to avoid any selection bias. One hundred and thirty-three participants (58\%) reported a degree in higher education (bachelor, master or doctoral) as their highest level of education, 75 participants (33\%) reported a high school degree, and 20 participants (9\%) a primary school degree. One-hundred and twenty-five participants (55\%) reported to be employed or self-employed, 89 participants (39\%) to study or to undergo vocational training and 14 $(6 \%)$ to be jobless.

\section{Procedure}

After providing informed consent, questionnaires on demographic information, TV series watching, depressive symptoms, impulsivity and the Big 5 personality traits were administered via an online platform. The time required for the survey was approximately $20 \mathrm{~min}$. Participants could take part in a price draw (3 vouchers of 25 EUR) to enhance motivation for study participation.

\section{Measures}

Binge-Watching Behaviour

If participants indicated that they had in the last 3 months watched 3 or more episodes of at least one TV series in one sitting, this was followed up with questions about which series they had watched (to take into account the duration of a single episode), and how many episodes they had watched. From this information, the total amount of time participants spent with binge-watching per week was calculated. In addition, the maximum number of episodes watched in a binge was assessed.

Negative Consequences Associated with Binge-Watching

To assess possible negative consequences that might be associated with binge-watching, we used 2 different questionnaire measures. First, we adapted the German short version of the InternetAddiction Test (s-IAT) [27, 28] with regard to binge-watching. The $s$-IAT [28] is a 12-item measure to assess the individuals' experience of possible negative consequences from the use of Internet applications and has already been adapted for different screen- based activities as suggested by Widyanto and McMurran [29] (e.g., Internet pornography, Internet gaming, online buying [3032]). In the present study, we modified the items to assess bingewatching by replacing terms like "Internet" or "online" with terms like "TV series watching" (e.g., "How often do you neglect duties to have more time to watch TV series?"). Responses are assessed on a 5 -point Likert scale ranging from 1 (= never) to 5 (= very often). The $s$-IAT consists of 2 sub-scales: loss of control/time management and craving/social problems. As the $s$-IAT was modified for the present study, no previous information on the psychometric quality of the $s-I A T_{\text {binge-watching }}$ is available, and we therefore conducted an exploratory factor analysis with data from the present sample. Results suggested a 3 factorial solution that explained $57.52 \%$ of the variance. While the first 2 factors comprised the items of the 2 sub-scales previously described, a third factor appeared, which, however, comprised only 2 items related to feelings of guilt and shame because of watching TV-series. We therefore decided to only calculate the 2 subscales loss of control/time management and craving/social problems; these had satisfying to good internal consistencies in our sample (Cronbach's $\alpha \geq 0.67$ ).

Second, we have previously developed and validated in 2 independent samples (unpublished data) a new scale (Binge-watching Effects Scale [BWES]) to assess the effects of binge-watching on every-day life, loss of self-control and automatized habitual behaviour, as these aspects are not addressed in other measures. Initially, 92 items were generated that focused primarily on issues of time management like excessive time investment or neglect of other tasks [28], facets of loss of self-control like difficulties in resisting temptations or breaking habits [33,34], and delay discounting [35] which have been related to problematic behavioural patterns $[16,17]$. The answers were given on a 6-point Likert scale ranging from 1 (= strongly disagree) to 6 (= strongly agree). To test psychometric quality of this questionnaire, data were collected in 2 waves independent from the present study. Data from the first sample $(n=229,166$ females; mean age 25.24, SD 4.83, range 18-50) was used to conduct an exploratory factor analysis with the aim to investigate the factor structure and to reduce the overall number of items; this resulted in a version with a 3 factorial structure comprising 30 items. Then, a confirmatory factor analysis was conducted with a second sample ( $n=219,162$ females; mean age 24.77, SD 6.13, range 18-60). Based on common criteria like standardized factor loadings and residual variances [36], further items were excluded to improve the model fits. This resulted in a 3-factorial structure with 16 items and good to excellent model fits (RMSEA $=0.06, \mathrm{CFI}=0.97$, TLI $=0.97$, SRMR $=0.03, \chi^{2}=186.95$ with $\left.p<0.001\right)$. The 3 subscales were named loss of control, neglect of duties and habit according to the items loaded on these scales (Appendix 1). In the present study, Cronbach's $\alpha$ for the different subscales ranged from 0.90 to 0.94 .

\section{Depressive Symptoms}

A German short form of the Center for Epidemiologic StudiesDepression Scale, the General Depression Scale (ADS-K) [37], was administered in the present study to screen for dispositional trait depressive symptoms. The $A D S-K$ comprises 15 items that are answered on a 4-point Likert scale ranging from 0 (= never) to 3 (= very often) resulting in a maximum score of 45 . Based on epidemiological studies [37] a score above 17 indicates clinically relevant symptoms. The ADS-K was chosen, as it was developed for the use in non-clinical samples. In the present sample, Cronbach's a was 0.91 . 
Table 1. Sample characteristics of participants reporting binge-watching and those reporting no binge-watching

\begin{tabular}{|c|c|c|c|}
\hline Variables & $\begin{array}{l}\text { Participants } \\
\text { reporting binge- } \\
\text { watching }(n=186)\end{array}$ & $\begin{array}{l}\text { Participants } \\
\text { reporting no binge- } \\
\text { watching }(n=42)\end{array}$ & $\begin{array}{l}\text { Statistics } \\
\left(t / X^{2}, p \text { value }\right)\end{array}$ \\
\hline \multicolumn{4}{|l|}{ Gender, $n(\%)$} \\
\hline Female & $119(80)$ & $29(20)$ & $5.11, \quad 0.15$ \\
\hline Male & $67(85)$ & $12(15)$ & \\
\hline Age, years, mean (SD) & $29.25(6.48)$ & $32.18(8.80)$ & $-1.98, \quad 0.05$ \\
\hline Depressive symptoms $(A D S-K)$, mean (SD) & $10.10(7.74)$ & $12.81(9.60)$ & $-1.96, \quad 0.05$ \\
\hline Impulsivity (BIS-15), mean (SD) & $32.33(6.54)$ & $32.50(7.20)$ & $-0.15, \quad 0.88$ \\
\hline Extraversion $(B F I-K)$, mean (SD) & $13.58(3.57)$ & $14.57(3.43)$ & $-1.64, \quad 0.10$ \\
\hline Agreeableness $(B F I-K)$, mean (SD) & $11.92(3.15)$ & $13.19(2.63)$ & $-2.42, \quad 0.02$ \\
\hline Conscientiousness (BFI-K), mean (SD) & $13.67(2.48)$ & $14.17(2.86)$ & $-1.15, \quad 0.25$ \\
\hline Neuroticism $(B F I-K)$, mean $(\mathrm{SD})$ & $12.32(3.39)$ & $12.14(3.31)$ & $0.31, \quad 0.76$ \\
\hline Openness $(B F I-K)$, mean (SD) & $19.66(3.10)$ & $21.21(2.96)$ & $-2.96,<0.01$ \\
\hline
\end{tabular}

ADS-K, General Depression Scale; BIS-15, Barratt Impulsiveness Scale; BFI-K, Big Five Inventory.

Impulsivity

The Barratt Impulsiveness Scale-15 [38] is a widely used measure in addiction research and was administered in the present study to assess trait impulsive behaviour. The Barratt Impulsiveness Scale-15 comprises 15 items answered on a 4-point Likert scale ranging from 1 (= never/rarely) to 4 (= always/very often) resulting in a maximum score of 60 . No norms are available. Three different dimensions (motor impulsivity, attentional impulsivity, non-planning impulsivity) and a global score can be calculated, which was used in the present study. Internal consistency for the global score was good (Cronbach's $\alpha \geq 0.84$ ).

Personality Traits

A short version of the Big 5 Inventory [39] relying on the 5-Factor model of personality [40] was administered. This version comprises 21 items to assess the personality traits neuroticism, conscientiousness, extraversion, agreeableness, and openness on a 5 -point Likert scale ranging from 1 (= not at all) to 5 (= very much). Cronbach's a for the different subscales ranged from 0.64 to 0.84 in the present sample.

\section{Statistical Analysis}

The predictive validity of depressive symptoms, impulsivity and their interaction and the variance explanation when considering further personality traits was analysed using stepwise hierarchical multiple linear regression analysis. Different analyses were performed with either loss of control, neglect of duties/social problems, or habitual binge-watching as dependent variables (as indicated by the different subscales of the $s-I A T_{\text {binge-watching }}$ and the BWES). In all analyses, gender was entered in the first step to control for possible confounding effects given that males and females might differ with regard to depressive symptoms, impulsivity and personality traits [41]. Then, depressive symptoms, impulsivity and the interaction term were entered in the second step. In the final step, the further personality traits were entered. All variables were centralized prior to this analysis [42]. A post hoc power analysis using $G^{*}$ Power (version 3.1.9.2) indicated that the recruited sample size was sufficient to detect small to medium-size effects with a power of $0.90-0.99$. The assump- tions of all statistical procedures applied were checked. In the case of violation of the assumption of normal distribution, the analyses were performed as intended given robustness of procedures against this violation. A significance level of $\alpha \leq 0.05$ was considered significant. All analyses were performed using IBM SPSS Statistics (version 24).

\section{Results}

\section{Binge-Watching Behaviour and Individual \\ Characteristics}

Binge-watching in the last 3 months as indicated by watching at least once $>2$ episodes of one series in one sitting was reported by 186 participants (82\%); 42 participants $(18 \%)$ did not report binge-watching. The mean maximal number of episodes of one series that were watched in one sitting was 7.37 (SD 4.42, range 3-23). Participants who reported binge-watching spent on average in the last 3 months $2.57 \mathrm{~h}$ per week (SD 2.69, range 1-20) watching series indicating a high variability with regard to the frequency of binge-watching. Bingewatchers compared to non-binge-watchers did not differ with regard to gender $\left(X^{2}=5.11, p=0.11\right)$, employment status $\left(X^{2}=5.21, p=0.25\right)$ or age $(t[226]=-1.98$, $p=0.053)$. The groups did not also differ with regard to the severity of depressive symptoms $(t[226]=-1.96, p=$ $0.051)$; the mean scores indicated a low severity of depressive symptoms for both groups (Table 1). In the binge-watching group, 29 participants (16\%) and in the non-binge-watching group 12 participants (29\%) achieved a score above 17 and statistical analysis indicated equal proportions of participants with clinically 
Table 2. Results of the multiple linear regression analysis to predict different negative aspects that might be associated with binge-watching $(n=228)$

\begin{tabular}{|c|c|c|c|c|c|c|c|c|c|}
\hline a Factors of the $s-I A T_{\text {binge watching }}$ & \multicolumn{3}{|c|}{ Loss of control/time management } & \multicolumn{6}{|c|}{ Craving/social problems } \\
\hline Depressive symptoms ( $A D S-K)$ & 0.12 & 1.67 & 0.10 & 0.16 & 2.10 & 0.04 & & & \\
\hline Impulsivity $(B I S-15)$ & 0.15 & 2.08 & 0.04 & 0.02 & 0.32 & 0.75 & & & \\
\hline Depressive symptoms $\times$ impulsivity & -0.05 & -0.76 & 0.45 & 0.01 & 0.17 & 0.87 & & & \\
\hline Conscientiousness $(B F I-K)$ & -0.15 & -2.01 & 0.05 & -0.06 & -0.78 & 0.44 & & & \\
\hline Neuroticism $(B F I-K)$ & 0.05 & 0.66 & 0.51 & 0.12 & 1.51 & 0.13 & & & \\
\hline Openness $(B F I-K)$ & -0.06 & -0.89 & 0.37 & -0.07 & -0.95 & 0.34 & & & \\
\hline$R^{2}$ & 0.18 & & & 0.09 & & & & & \\
\hline b Factors of the $B W E S$ & \multicolumn{3}{|c|}{ Loss of control } & \multicolumn{3}{|c|}{ Neglect } & \multicolumn{3}{|l|}{ Habit } \\
\hline Depressive symptoms (ADS-K) & 0.10 & 1.31 & 0.19 & 0.24 & 3.43 & 0.00 & -0.05 & -0.65 & 0.52 \\
\hline Impulsivity $(B I S-15)$ & 0.23 & 3.05 & 0.00 & 0.17 & 2.36 & 0.02 & -0.10 & -1.31 & 0.19 \\
\hline Depressive symptoms $\times$ impulsivity & 0.06 & 0.91 & 0.36 & -0.03 & -0.43 & 0.67 & 0.04 & 0.53 & 0.60 \\
\hline Extraversion $(B F I-K)$ & 0.08 & 1.05 & 0.29 & -0.05 & -0.74 & 0.46 & -0.11 & -1.51 & 0.13 \\
\hline Agreeableness $(B F I-K)$ & 0.02 & 0.31 & 0.76 & 0.00 & -0.07 & 0.95 & -0.07 & -1.06 & 0.29 \\
\hline Conscientiousness (BFI-K) & 0.01 & 0.12 & 0.91 & -0.23 & -3.18 & 0.00 & -0.17 & -2.19 & 0.03 \\
\hline Neuroticism $(B F I-K)$ & 0.07 & 0.89 & 0.37 & -0.01 & -0.19 & 0.85 & 0.08 & 1.00 & 0.32 \\
\hline Openness (BFI-K) & -0.07 & -1.09 & 0.28 & 0.05 & 0.82 & 0.41 & -0.09 & -1.24 & 0.22 \\
\hline$R^{2}$ & 0.15 & & & 0.24 & & & 0.08 & & \\
\hline
\end{tabular}

$\beta$ is the standardized regression coefficient.

s-IAT $T_{\text {binge-watching, }}$, short version of the Internet Addiction Test adapted for binge-watching; BWES, Binge-watching Effects Scale; ADSK, General Depression Scale; BIS-15, Barratt Impulsiveness Scale; BFI-K, Big Five Inventory.

relevant depressive symptoms in both groups $\left(X^{2}=3.91\right.$, $p=0.07)$. With regard to the personality trait variables, binge-watchers compared to non-binge watchers reported to be less open $(t[226]=-2.96, p<0.01)$ and less agreeable $(t[226]=-2.42, p=0.02)$, while all other differences achieved no statistical significance (Table 1 for further details).

\section{Prediction of Negative Consequences Associated with Binge-Watching \\ Loss of Control}

A significant model with regard to the subscale loss of control/time management of thes-IA $T_{\text {binge-watching }}$ emerged in the first step $\left(F[1,226]=15.63, p<0.000, R^{2}=0.07\right)$ with female gender being positively associated with this subscale. Entering depressive symptoms, impulsivity and the interaction term significantly improved the model $\left(\Delta R^{2}=0.09, F[4,223]=10.11, p<0.000\right)$, with impulsiv- ity emerging as significant predictor variable. The interaction between impulsivity and depressive symptoms was not significant. Entering the further personality trait variables did not significantly improve the model (Table 2a, for details of the final model).

Similar results were observed with regard to the subscale loss of control of the BWES. Thus, gender emerged as significant predictor variable in the first step $\left(R^{2}=0.06\right.$, $F[1,226]=14.29, p<0.001)$ indicating that female gender was associated with more severe loss of control. Entering depressive symptoms, impulsivity and the interaction term significantly improved the model $\left(\Delta R^{2}=0.08, F[4\right.$, $223]=8.89, p<0.000)$ with impulsivity as the only significant predictor variable. Entering the further variables in the final step did not improve the model (Table 2b). Figure 1 illustrates the association between impulsivity, depressive symptoms and the subscale loss of control of the BWES. 


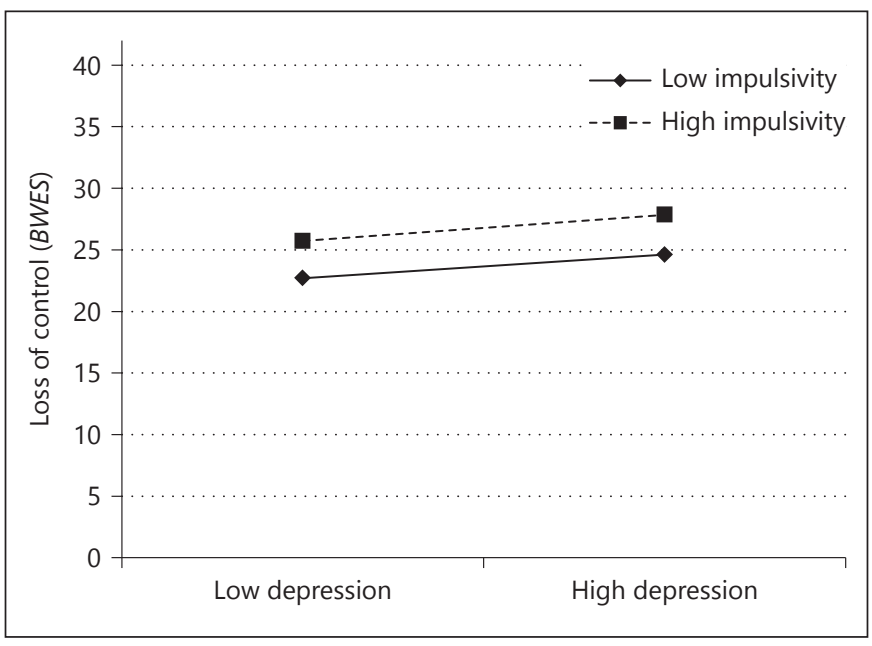

Fig. 1. Simple slope analysis based on the results of the regression analysis to predict loss of control (assessed with the BWES): The simple slopes of the regression lines representing high $(t=1.84, p=$ $0.04)$ and low impulsivity $(t=2.05, p=0.07)$ indicated no interaction effect with depressive symptoms. BWES, Binge-watching Effects Scale.

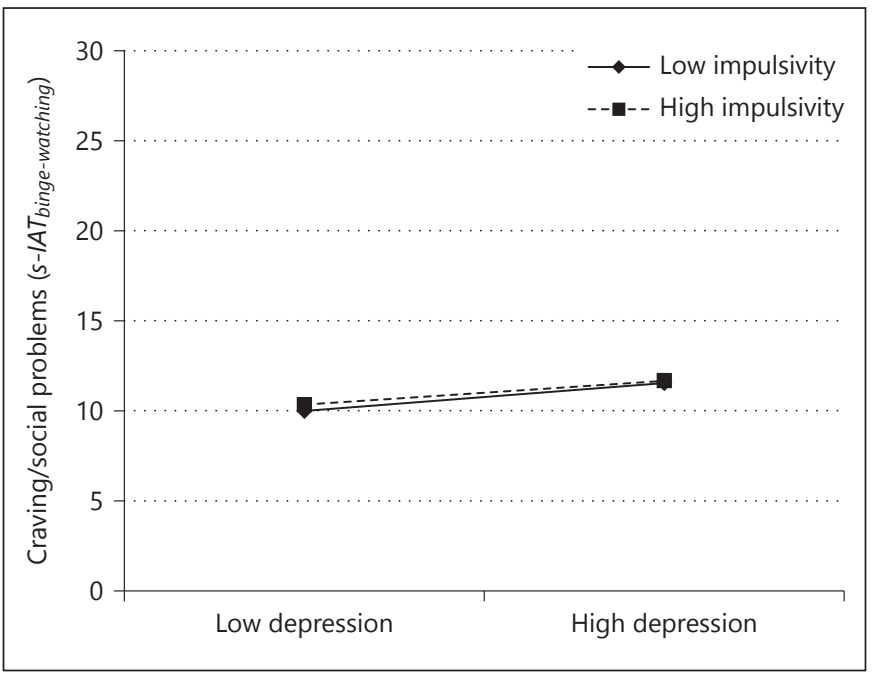

Fig. 2. The simple slopes of the regression lines representing high and low impulsivity differed both significantly from zero $(t \geq 2.57, p<$ $0.01)$ and indicated no interaction effect with depression. The dependent variable was craving/social problems (assessed with the $s$ $\left.I A T_{\text {binge-watching }}\right) . s-I A T$, short version of the Internet Addiction Test.

Craving/Social Problems and Neglect of Other Duties With regard to the subscale craving/social problems of the $s$-IAT $T_{\text {binge-watching, }}$ a significant model emerged in the first step $\left(F[1,226]=5.20, p=0.02, R^{2}=0.02\right)$, as gender was again a significant predictor variable and female gender associated with more severe craving and social prob- lems. However, the model significantly improved when depressive symptoms, impulsivity and the interaction term were entered $\left(\Delta R^{2}=0.05, F[4,223]=4.41, p=0.002\right)$, but only depressive symptoms emerged as significant predictor variable indicating an association between depressive symptoms and more severe craving and social problems. Again, the model did not significantly improve by entering the further personality trait variables (Table $2 \mathrm{a}$, for details of the final model and Fig. 2 for an illustration).

With regard to the subscale neglect of the BWES gender emerged again as a significant predictor variable and female gender was associated with higher scores on the subscale neglect; the model was significant $(F[1,226]=$ 10.37, $\left.p=0.001, R^{2}=0.04\right)$. Entering depressive symptoms, impulsivity and the interaction term significantly improved the model $\left(\Delta R^{2}=0.16, F[4,223]=14.20, p<\right.$ 0.001 ) with depressive symptoms and impulsivity, but not their interaction, as significant predictors variables. Entering the remaining personality traits further improved the model significantly $\left(\Delta R^{2}=0.04, F[9,218]=\right.$ $7.80, p<0.001)$ with conscientiousness being negatively associated with neglect of duties (Table 2).

\section{Habitual Binge-Watching}

With regard to the subscale habit of the BWES, the model was only significant in the final step when the further personality traits were entered $(F[9,218]=2.04, p=$ $0.04, R^{2}=0.08$ ) and again conscientiousness emerged as protective factor, as it was associated with less habitual binge-watching (Table $2 \mathrm{~b}$ ).

\section{Discussion}

The aim of the present study was to assess how depressive symptoms, impulsivity and their potential interaction are related to the consequences of binge-watching. In addition, the possible association of the Big 5 personality traits neuroticism, conscientiousness, extraversion, agreeableness, and openness with consequences from bingewatching was assessed. We differentiated between loss of control over binge-watching, neglect of duties and social problems as well as habitual binge-watching as indicators of negative consequences from binge-watching. Our results suggest that impulsivity and depressive symptoms need to be considered as 2 different pathways independently contributing to possible problematic binge-watching. Thus, higher scores of impulsivity were associated with both loss of control over binge-watching (as assessed 
with the $s-I A T_{\text {bingewatching }}$ and the $B W E S$ ) and neglect of duties (BWES). In line with this, Riddle et al. [24] recently reported that impulsivity is associated with unintentional binge-watching. Our results extend those findings as we found that impulsivity makes individuals not only vulnerable to loss of control over binge-watching, but also to continue binge-watching at the expense of duties. An association between impulsivity as a personality trait and problematic behavioural patterns is also found with regard to a number of other behaviours. For example, there is strong evidence for an association between impulsivity and substance-use disorder or gambling disorder [19]. Consequently, it can be hypothesized that impulsivity puts individuals at risk to overindulge in positive activities and to develop problematic behavioural patterns.

With regard to depressive symptoms, higher scores significantly predicted neglect of duties (BWES) and social problems ( $s-I A T_{\text {bingewatching }}$ ), but not loss of control or binge-watching as a habit. This finding expands results of previous studies as, for example, Abdel-Azim and Ahmed [5] found higher depression scores in binge-watchers compared to non-binge-watchers, but negative consequences of binge-watching were not investigated. Given that in the present study a trend for more severe depressive symptoms as well as a higher proportion of participants with clinically relevant depressive symptoms in the non-binge-watching group was observed, the differentiation between binge-watching per se and problematic binge-watching seems to be crucial. Our results suggest that with increasing severity of depressive symptoms binge-watching might serve as a distraction from negative thoughts and feelings with neglect of duties and social problems as the main consequences. Given the cross-sectional character of our study, we cannot exclude that individuals might neglect their duties independently from binge-watching, for example due to a general reduction of energy and drive as a symptom of depression. Given the specific nature of the 2 questionnaires administered asking for example about "watching episodes instead of completing one's duties" (example item of the BWES), we think it rather likely that higher depression scores lead to binge-watching, which results in the neglect of duties and social problems. However, future longitudinal studies are warranted to investigate this hypothesized mediation.

Another finding that is important to consider is that female gender was a significant predictor with regard to negative consequences from binge-watching and remained significant when the further individual variables were entered in the regression analysis. The observation that females might be more sensitive to the development of specific deleterious behavioural patterns is not without precedence. For example, with regard to pathological buying, Müller et al. [43] reported that females achieved higher scores than males with regard to loss of control and negative consequences from excessive buying behaviour. These findings indicate that gender-differences might affect the development of various problematic behavioural patterns. Future studies are warranted to better understand these effects with regard to the phenomenon of binge-watching.

In line with studies that reported that conscientiousness is a protective factor against the development of behavioural addictions $[44,45]$ and also with regard to problematic binge watching [15], conscientiousness emerged in the present study as a protective factor against neglect of duties, binge-watching as a habit and loss of control. However, none of the other personality trait variables explained any significant proportion of variance regarding negative consequences from binge-watching in addition to impulsivity, depressive symptoms, their interaction, and conscientiousness, although binge-watchers compared to non-binge-watchers reported to be less agreeable and open. This finding is in contrast to the results from Toth-Kiraly et al. [15] who found that high-engagement viewers, who are characterized by a higher time spent binge-watching and problematic series watching compared to low- and medium engagement viewers, achieved also higher neuroticism scores than the other groups. However, as we assessed in the present study the contribution of neuroticism after entering severity of depressive symptoms and impulsivity in the regression model, this suggests that, from the variables assessed, impulsivity and depressive symptoms are the main variables that need to be considered when identifying individuals at risk to develop negative consequences from binge-watching. Nevertheless, the regression analysis with the different dependent variables representing negative consequences from binge-watching resulted in an $R^{2}$ ranging from 0.08 (for the subscale habit of the BWES) to 0.24 (for the subscale neglect of the BWES). Thus, the variance explained by impulsivity, depressive symptoms and conscientiousness was rather low suggesting that other variables, which have not been assessed, might have a more pronounced impact on binge-watching. Future studies are therefore warranted that take into account further variables (e.g., emotion regulation problems, self-control problems, attentional problems) to enhance our understanding of the transition from a functional behaviour to a dysfunctional activity associated with a deleterious impact on everyday life. One aspect that might be interesting to investigate comprises 
difficulties in emotion regulation. As recently reported by Flayelle et al. [46] key motivational aspects involved in binge-watching are emotional enhancement and affect regulation. Thus, individuals experiencing negative mood and having difficulties to apply functional coping mechanisms might be more prone to engage in problematic binge-watching as a kind of copying strategy. For future research, it is also important to consider individual characteristics that are unique to the development of problematic binge-watching. In the field of addiction research, impulsivity and depressive symptoms are considered crucial contributors to the development of both substance use disorders and behavioural addictions and are also known to worsen during the course of addiction thereby contributing to the maintenance of problematic behavioural patterns [47-49]. While our findings suggest that similar mechanisms are important with regard to binge-watching, they also underline the need to elucidate the role of other factors that contribute to the development of severe negative consequences and individual distress. One such aspect might be sensation seeking, which was recently shown to boost the effects of different motivations to binge-watching [50].

When interpreting the findings of the present study, some critical aspects should be acknowledged. First, while $82 \%$ of the participants assessed in the present study reported binge-watching based on the definition suggested by Walton-Pattison et al. [4], the variability with regard to the weekly time spent binge-ranged from 1 to $20 \mathrm{~h}$ with a mean time of $2.57 \mathrm{~h} /$ week spent binge-watching. This suggests that it is important when considering problematic binge-watching not to rely on the sole criterion of the number of episodes watched in one sitting, but also to take into account the regularity of this behaviour or, may be even more important, whether it is associated with negative consequences (e.g., loss of control, neglect of duties) as assessed in the present study. Thus, future studies are warranted to enhance our understanding of the differentiation of binge-watching as a popular leisure activity from binge-watching as a problematic behavioural pattern.

In addition, study participants were recruited via Facebook and we cannot assume that this resulted in a representative or clinically relevant sample limiting generalization of our results. For example, depressive symptoms were rather low and different results might have been observed in more severe depressed participants. In line with this, it should be acknowledged that no exclusion criteria (e.g., psychosis) were defined which might have affected our findings, for example by including participants whose viewing patterns of TV-series are not representative for the general population. Further, recruitment resulted in an unequal gender distribution with a higher proportion of female participants. Given the present findings, future studies should investigate gender differences systematically. Finally, the study design was cross-sectional and retrospective and thus, no clear causal interpretations can be drawn. Consequently, longitudinal studies are warranted to assess the causality of the observed associations and the stability of binge-watching behaviour as well as associated consequences, which was not possible to address in the current study.

To conclude, the results of the present study suggest that binge watching is a highly prevalent consume pattern of TV-series, but that it is important to differentiate between the time spent binge watching and negative consequences from binge-watching as reflected in loss of control, craving and social problems, and neglect of duties. Impulsivity and depressive symptoms seem to be 2 independent pathways that contribute to the development of different consequences from binge watching, while conscientiousness acts as protective factor. Future longitudinal studies are warranted to replicate this finding, to clarify the causal nature of these individual characteristics and to elucidate the role of other vulnerability factors that might put individuals at risk to develop problematic viewing patterns.

\section{Acknowledgement}

The authors wish to thank Svea Delsing, Katharina Kloppenborg and Lilyana Sharlandzhieva for their support with regard to the collection and analysis of the data.

\section{Statement of Ethics}

The study was conducted in accordance with the Declaration of Helsinki and was approved by the local Ethics Committee of the University of Bamberg.

\section{Disclosure Statement}

The authors declare that they have no conflicts of interest to disclose.

\section{Funding Sources}

No financial support was received for this study. 


\section{Appendix 1}

\section{Binge-Watching Effects Scale}

Factor 1: "Loss of Control"

1. I often watch more episodes than I intended.

2. At the end of an episode, I indulge in the desire to watch another one.

3. After one episode, I have a strong urge to watch another one.

4. I often find myself saying: "Just one more episode".

5. I can hardly stop watching episodes, when I have started once.

6. After watching an episode, it often happens that I watch an unplanned other one.

7. Due to watching episodes I go to sleep later.
Factor 2: "Neglect of Duties"

1. I watch episodes instead of completing my duties.

2. I neglect important tasks because of watching episodes.

3. I would rather neglect important tasks than stop watching episodes.

4. I postpone my school-, university- or job-related tasks in order to watch episodes.

5. I leave tasks undone because I prefer watching episodes.

6. Important tasks become delayed because I watch episodes.

Factor 3: "Habit"

1. Watching episodes is a habit for me.

2. Watching episodes is part of my everyday life.

3. Watching episodes is a daily desire.

All items are marked on a Likert-scale ranging from $1=$ not at all to $6=$ very much.

\section{References}

1 Jenner M. Binge-watching: Video-on-demand, quality TV and mainstreaming fandom. Int J Cult Stud. 2017;20(3):304-20.

2 Mittell J. Complex TV: The Poetics of Contemporary Television Storytelling: NYU Press; 2015.

3 Alter AL. Irresistible: The rise of addictive technology and the business of keeping us hooked. New York: Penguin Press; 2017.

4 Walton-Pattison E, Dombrowski SU, Presseau J. 'Just one more episode': frequency and theoretical correlates of television binge watching. J Health Psychol. 2018 Jan;23(1): $17-24$.

5 Abdel-Azim A, Ahmed M. New era of TVwatching behavior: binge watching and its psychological effects. Media Watch. 2017;8: 192-207.

6 Flayelle M, Maurage P, Vögele C, Karila L, Billieux J. Time for a plot twist: beyond confirmatory approaches to binge-watching research. Psychol Pop Media Cult. 2019;8(3): 308-18.

7 Pittman M, Steiner E. Transportation or Narrative Completion? Attentiveness during Binge-Watching Moderates Regret. Soc Sci. 2019;8(3):99.

8 Flayelle M, Maurage P, Billieux J. Toward a qualitative understanding of binge-watching behaviors: A focus group approach. J Behav Addict. 2017 Dec;6(4):457-71.

9 Exelmans L, Van den Bulck J. binge viewing, sleep, and the role of pre-sleep arousal. J Clin Sleep Med. 2017 Aug;13(8):1001-8.

10 Camart N, Zebdi R, Bouvet C. Between pleasure and risk - the psychology of TV series watching: An empirical study with 400 participants. In: Camart N, Lefait S, Paquet-Deyris AM, Romo L, editors. Combining aesthetic and psychological approaches to TV series addiction. Newcastle upon Tyne: Cambridge Scholars Publishing; 2018. pp. 36-54.

11 Orosz G, Bőthe B, Tóth-Király I. The development of the Problematic Series WatchingS- cale (PSWS). J Behav Addict. 2016 Mar;5(1): 144-50.

12 Billieux J, Schimmenti A, Khazaal Y, Maurage P, Heeren A. Are we overpathologizing everyday life? A tenable blueprint for behavioral addiction research. J Behav Addict. 2015 Sep; $4(3): 119-23$.

13 A bad habit for your health?: An exploration of psychological factors for binge-watching behavior; 2015.

14 Deleuze J, Long J, Liu TQ, Maurage P, Billieux J. Passion or addiction? Correlates of healthy versus problematic use of videogames in a sample of French-speaking regular players. Addict Behav. 2018 Jul;82:114-21.

15 Tóth-Király I, Bőthe B, Tóth-Fáber E, Hága G, Orosz G. Connected to TV series: quantifying series watching engagement. J Behav Addict. 2017 Dec;6(4):472-89.

16 Brand M, Wegmann E, Stark R, Müller A, Wölfling K, Robbins TW, et al. The Interaction of Person-Affect-Cognition-Execution (I-PACE) model for addictive behaviors: Update, generalization to addictive behaviors beyond internet-use disorders, and specification of the process character of addictive behaviors. Neurosci Biobehav Rev. 2019 Sep; 104:1-10.

17 Brand M, Young KS, Laier C, Wölfling K, Potenza MN. Integrating psychological and neurobiological considerations regarding the development and maintenance of specific Internet-use disorders: An Interaction of Person-AffectCognition-Execution (I-PACE) model. Neurosci Biobehav Rev. 2016 Dec;71:252-66.

18 Tukachinsky R, Eyal K. The psychology of marathon television viewing: antecedents and viewer involvement. Mass Commun Soc. 2018;21(3):1-21.

19 Billieux J, Gay P, Rochat L, Van der Linden M. The role of urgency and its underlying psychological mechanisms in problematic behaviours. Behav Res Ther. 2010 Nov;48(11): 1085-96.
20 Cao F, Su L, Liu T, Gao X. The relationship between impulsivity and Internet addiction in a sample of Chinese adolescents. Eur Psychiatry. 2007 Oct;22(7):466-71.

21 Choi JS, Park SM, Roh MS, Lee JY, Park CB, Hwang JY, et al. Dysfunctional inhibitory control and impulsivity in Internet addiction. Psychiatry Res. 2014 Feb;215(2) 424-8.

22 Barratt ES. Impulsiveness subtraits: Arousal and information processing. In: Spence JT, Izard CE, editors. Motivation, emotion, and personality. North-Holland. the Netherlands: Elsevier Science; 1985. pp. 137-46.

23 Patton JH, Stanford MS, Barratt ES. Factor structure of the Barratt impulsiveness scale. J Clin Psychol. 1995 Nov;51(6):768-74.

24 Riddle K, Peebles A, Davis C, Xu F, Schroeder E. The addictive potential of television binge watching: comparing intentional and unintentional binges. Psychol Pop Media Cult. 2018;7(4):589-604.

25 Orosz G, Vallerand R, Bőthe B, Tóth-Király I, Paskuj B. On the correlates of passion for screen-based behaviors: the case of impulsivity and the problematic and non-problematic Facebook use and tv series watching. Pers Individ Dif. 2016;101:167-76.

26 Whiteside SP, Lynam DR. The Five Factor Model and impulsivity: using a structural model of personality to understand impulsivity. Pers Individ Dif. 2001;30(4):669-89.

27 Young KS, Rogers RC. The relationship between depression and Internet addiction. $\mathrm{Cy}$ berpsychol Behav. 1998;1(1):25-8.

28 Pawlikowski M, Altstötter-Gleich C, Brand M. Validation and psychometric properties of a short version of Young's Internet Addiction Test. Comput Human Behav. 2013;29(3): 1212-23.

29 Widyanto L, McMurran M. The psychometric properties of the internet addiction test. Cyberpsychol Behav. 2004 Aug;7(4): 443-50. 
30 Brand M, Laier C, Pawlikowski M, Schächtle U, Schöler T, Altstötter-Gleich C. Watching pornographic pictures on the Internet: role of sexual arousal ratings and psychological-psychiatric symptoms for using Internet sex sites excessively. Cyberpsychol Behav Soc Netw. 2011 Jun;14(6):371-7.

31 Pawlikowski M, Brand M. Excessive Internet gaming and decision making: do excessive World of Warcraft players have problems in decision making under risky conditions? Psychiatry Res. 2011 Aug; 188(3): 428-33.

32 Trotzke P, Starcke K, Müller A, Brand M. Pathological buying online as a specific form of Internet addiction: A model-based experimental investigation. PLoS One. 2015 Oct; 10(10):e0140296.

33 Tangney JP, Baumeister RF, Boone AL. High self-control predicts good adjustment, less pathology, better grades, and interpersonal success. J Pers. 2004 Apr;72(2):271-324.

34 Bertrams A, Dickhäuser O. Messung dispositioneller Selbstkontroll-Kapazität. Diagnostica. 2009;55(1):2-10.

35 Mischel W, Ebbesen EB, Zeiss AR. Cognitive and attentional mechanisms in delay of gratification. J Pers Soc Psychol. 1972 Feb;21(2): 204-18.

36 Bentler PM, Yuan KH. Structural Equation Modeling with Small Samples: test Statistics.
Multivariate Behav Res. 1999 Apr;34(2):18197.

37 Hautzinger M, Bailer M, Hofmeister D, Keller F. ADS: Allgemeine Depressionsskala. Hogrefe; 2012.

38 Meule A, Vögele C, Kübler A. Psychometrische Evaluation der deutschen Barratt Impulsiveness Scale - Kurzversion. Diagnostica. 2011;57(3):126-33.

39 Rammstedt B, John OP. Kurzversion des Big Five Inventory (BFI-K). Diagnostica. 2005; 51(4):195-206.

40 Costa PT Jr, McCrae RR. Normal personality assessment in clinical practice: The NEO Personality Inventory. Psychol Assess. 1992;4(1): 5-13.

41 Feingold A. Gender differences in personality: a meta-analysis. Psychol Bull. 1994 Nov; 116(3):429-56

42 Cohen J, Cohen P, West SG, Aiken LS. Applied multiple regression/correlation analysis for the behavioral sciences. 3rd ed. Mahwah, NJ, US: Lawrence Erlbaum Associates Publishers; 2003.

43 Müller A, Trotzke P, Mitchell JE, de Zwaan M, Brand M. The pathological buying screener: development and psychometric properties of a new screening instrument for the assessment of pathological buying symptoms. PLoS One. 2015 Oct;10(10):e0141094.

44 Andreassen CS, Griffiths MD, Gjertsen SR, Krossbakken E, Kvam S, Pallesen S. The rela- tionships between behavioral addictions and the five-factor model of personality. J Behav Addict. 2013 Jun;2(2):90-9.

45 Zhou Y, Li D, Li X, Wang Y, Zhao L. Big five personality and adolescent Internet addiction: the mediating role of coping style. Addict Behav. 2017 Jan;64:42-8.

46 Flayelle M, Canale N, Vögele C, Karila L, Maurage P, Billieux J. Assessing binge-watching behaviors: Development and validation of the "Watching TV Series Motives" and "Binge-watching Engagement and Symptoms" questionnaires. Comput Human Behav. 2019;90:26-36.

47 Kraut R, Kiesler S, Boneva B, Cummings J, Helgeson V, Crawford A. Internet paradox revisited. J Soc Issues. 2002;58(1):49-74.

48 Orsal O, Orsal O, Unsal A, Ozalp SS. Evaluation of Internet addiction and depression among university students. Procedia Soc Behav Sci. 2013;82:445-54.

49 Czapla M, Simon JJ, Richter B, Kluge M, Friederich HC, Herpertz S, et al. The impact of cognitive impairment and impulsivity on relapse of alcohol-dependent patients: implications for psychotherapeutic treatment. Addict Biol. 2016 Jul;21(4):873-84.

50 Shim H, Kim KJ. An exploration of the motivations for binge-watching and the role of individual differences. Comput Human Behav. 2018;82:94-100. 